\title{
Percutaneous "edge-to-edge" leaflet repair in patient with primary mitral valve regurgitation
}

\author{
Giulio Rodinò, Giulia Masiero, Giuseppe Tarantini \\ Department of Cardiac, Thoracic, Vascular Science and Public Health, University of Padova, Padova 35128, Italy.
}

Correspondence to: Dr. Giuseppe Tarantini, Department of Cardiac, Thoracic and Vascular Science, University of Padova, Via Giustiniani 2, Padova 35128, Italy. E-mail: giuseppe.tarantini.1@gmail.com

How to cite this article: Rodinò G, Masiero G, Tarantini G. Percutaneous "edge-to-edge" leaflet repair in patient with primary mitral valve regurgitation. Mini-invasive Surg 2020;4:70. http://dx.doi.org/10.20517/2574-1225.2020.55

Received: 8 Jun 2020 First Decision: 27 Jul 2020 Revised: 7 Aug 2020 Accepted: 19 Aug 2020 Published: 16 Oct 2020

Academic Editor: Azeem Latib Copy Editor: Cai-Hong Wang Production Editor: Jing Yu

\begin{abstract}
Mitral regurgitation (MR) is the most common left-sided heart valve disease in developed countries with a constantly rising number of patients requiring hospitalization or intervention. Organic MR is defined as a primary structural abnormality of the mitral valve (MV) apparatus which may be caused by a broad set of pathological processes, among which myxomatous degeneration of the leaflets causing MV prolapse is the most common. If left untreated, chronic severe MR leads to serious adverse outcomes, from heart failure to death, but medical therapy is unable to change the natural history of the disease. Surgical correction, by means of valve repair or replacement, is the gold standard for the treatment of symptomatic patients with severe primary MR. However, surgery is not feasible for a large percentage of patients because of old age, reduced left ventricular ejection fraction and the presence of severe comorbidities. Therefore, in recent years, several percutaneous therapeutic alternatives suitable for high or prohibitive surgical risk patients were developed. In this review we discuss the transcatheter treatment of primary MR, from available evidence to technical practice, with a focus on the percutaneous "edge-to-edge" leaflet repair performed with the MitraClip System and the PASCAL Repair System.
\end{abstract}

Keywords: Degenerative mitral valve disease, mitral regurgitation, mitral insufficiency, MitraClip, PASCAL

\section{INTRODUCTION}

Mitral regurgitation (MR) is the most common left-sided heart valve disease in developed countries with a prevalence that increases with age (from $0.5 \%$ among subjects $18-44$ years old to $9.3 \%$ in the population

\footnotetext{
(@) $(0$

(C) The Author(s) 2020. Open Access This article is licensed under a Creative Commons Attribution 4.0 International License (https://creativecommons.org/licenses/by/4.0/), which permits unrestricted use, sharing, adaptation, distribution and reproduction in any medium or format, for any purpose, even commercially, as long as you give appropriate credit to the original author(s) and the source, provide a link to the Creative Commons license, and indicate if changes were made.
}

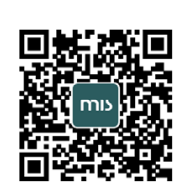


over 75 years of age), which in the last decades has led a to a sharp rise in the number of patients requiring hospitalization or intervention ${ }^{[1]}$. It is acknowledged that an organic (or primary) and a functional (or secondary) etiology of MR can be distinguished, and these two entities carry different prognosis and management ${ }^{[2]}$. The purpose of the current review is to outline the percutaneous treatment of primary MR, from available evidence to technical practice, with a focus on transcatheter "edge-to-edge" leaflet repair.

\section{ETIOLOGY AND TREATMENT OF PRIMARY MR}

Organic MR is defined as a primary structural abnormality of the mitral valve (MV) apparatus. Its etiology is largely dominated by myxomatous degeneration of the leaflets (which ranges from fibroelastic deficiency to Barlow's disease), followed by rheumatic disease, infective endocarditis, connective tissue and ischemic disease, congenital malformations, and iatrogenic (radiation therapy or drugs) and traumatic lesions ${ }^{[3,4]}$. Fibroelastic deficiency usually presents with thin transparent leaflets with focal prolapse or flail due to chordal rupture, while Barlow's disease hallmarks are multi-segment prolapse involving one or both leaflets in a valve with significant myxomatous changes, excess leaflet tissue and dilated annulus. Between these two phenotypes, a broad spectrum of degenerative disease is found in clinical practice ${ }^{[5]}$. Regardless of the anatomical background, MV prolapse is the most common cardiac valvular anomaly in developed countries affecting approximately $2 \%$ of the general population. It is associated with a variable degree of MR, with most patient having trivial or mild regurgitation; previous studies have found a $6 \%$ prevalence of a severe degree of the disease in the outpatient population with valve prolapse ${ }^{[6,7]}$. However, very little data are available in these patients regarding the progression of MR severity and the associated risk factors ${ }^{[8,9]}$. Left untreated, chronic severe MR may lead to left ventricular (LV) remodeling because of volume overload, myocardial dysfunction, heart failure, left atrial dilatation, atrial fibrillation and pulmonary hypertension. Surgical correction, by means of valve repair or replacement, is the gold standard for the treatment of symptomatic patients with severe primary $\mathrm{MR}^{[2]}$. The optimal timing for intervention has to be according to symptom onset, worsening of LV function, significant LV dilatation, or development of atrial fibrillation or pulmonary hypertension. Despite the lack of randomized clinical trials comparing the results of valve replacement and repair, it is widely accepted that valve repair is the preferred treatment, when it is feasible when and a durable repair is likely ${ }^{[2]}$. However, symptomatic patients are frequently denied surgical treatment mainly because of impaired LV ejection fraction, older age and comorbidities ${ }^{[3,10]}$. Therefore, in recent years, great effort was made to develop less invasive, percutaneous therapeutic alternatives suitable for high or prohibitive surgical risk patients. Possible catheter-based approaches for the treatment of MR include transapical or transseptal valve repair or replacement, placement of annular tightening devices, and insertion of artificial chordae. The "edge-to-edge" surgical repair technique, making a "double-orifice" MV, was the first to be adapted for the percutaneous approach with the MitraClip System (Abbott Vascular, Santa Clara, CA, USA), reaching over time more than 70,000 implants worldwide, since its first use in humans in $2003^{[11]}$. Later in 2019, the new PASCAL repair system (Edwards Lifesciences, Irvine, CA, USA) received CE mark for the percutaneous "edge-to-edge" repair treatment of MR, further expanding the therapeutic options available to the interventional cardiologist and the population eligible for treatment. As a matter of fact, current guidelines recommend a percutaneous edge-to-edge repair for the treatment of patients with symptomatic moderate-to-severe or severe primary MR who fulfill echocardiographic criteria of eligibility and are judged inoperable or at high surgical risk by the Heart Team evaluation (Class IIb, LOE C) ${ }^{[2]}$.

\section{TECHNICAL ASPECTS OF TRANSCATHETER MV “EDGE-TO-EDGE” LEAFLET REPAIR}

Proper patient selection with preoperative echocardiography using both $2 \mathrm{D}$ and $3 \mathrm{D}$ transesophageal echocardiography (TEE) is mandatory to confirm MR severity and define its mechanism while evaluating anatomic eligibility for an "edge-to-edge" transcatheter repair and, ultimately, achieve satisfactory results $^{[2,12]}$. In the early years of MitraClip usage, eligibility was evaluated according to the preliminary 
Table 1. Classification of MV morphology based on anatomical criteria for MitraClip implantation procedure

\begin{tabular}{|c|c|c|}
\hline $\begin{array}{l}\text { Optimal valve morphology } \\
\text { Beginner operator }\end{array}$ & $\begin{array}{c}\text { Possible valve morphology } \\
\text { Average operator }\end{array}$ & $\begin{array}{l}\text { Tough/unsuitable valve morphology } \\
\text { Expert operator }\end{array}$ \\
\hline Central pathology (A2/P2 scallops) & $\begin{array}{l}\text { Commissural pathology (A1/P1 or A3/P3 } \\
\text { scallops) }\end{array}$ & Barlow's syndrome, flail in multiple scallops \\
\hline No calcification & $\begin{array}{l}\text { Mild calcification outside grasping zone, } \\
\text { annulus calcification, previous annuloplasty }\end{array}$ & Significant calcification of grasping zone \\
\hline $\mathrm{MVA}>4 \mathrm{cmq}$ & MVA $>3 \mathrm{cmq}$, preserved mobility & - \\
\hline Posterior leaflet length $\geq 10 \mathrm{~mm}$ & Posterior leaflet length 7-10 mm & Posterior leaflet length $<7 \mathrm{~mm}$ \\
\hline Tenting height $<11 \mathrm{~mm}$ & Tenting height > 11 mm & - \\
\hline Normal leaflet thickness and mobility & Restricted leaflet motion during systole & $\begin{array}{l}\text { Restricted leaflet motion during systole and } \\
\text { diastole, rheumatic disease }\end{array}$ \\
\hline Flail gap $<10 \mathrm{~mm}$ and width $<15 \mathrm{~mm}$ & $\begin{array}{l}\text { Flail width }>15 \mathrm{~mm} \text { with dilated annulus } \\
\text { (multiple clip implantation) }\end{array}$ & - \\
\hline
\end{tabular}

MV: mitral valve; MVA: mitral valve area

EVEREST trial inclusion and exclusion criteria ${ }^{[13]}$; nowadays, thanks to the spread of the procedure, the growing experience of the operators and several technical improvements have allowed broadening the spectrum of suitable MV lesions, including some that were previously considered not feasible with good results, particularly in high-volume centers. Therefore, concerning eligibility for the procedure, MV anatomies may be divided into "optimal", "challenging" and "advanced", requiring increasing operator experience. Absolute contraindications to the percutaneous "edge-to-edge" technique are still represented by very short posterior leaflet, high degree of calcification in leaflet grasping area, MV area $<3 \mathrm{~cm}^{2}$ and rheumatic $\mathrm{MR}^{[14]}$ [Table 1]. An interesting topic is the management of $\mathrm{MR}$ of mixed or undetermined etiologies, but data in this regard are still scant. To date, only few registries report an incidence ranging from $3 \%$ to $10 \%$ in real-world practice; however, their results have focused only on degenerative and functional etiology for outcome data analysis. As a matter of fact, standardized criteria to define a "mixed etiology" are lacking, making it difficult to achieve a shared definition among different studies, and in most cases a predominant etiology between organic and functional may be individualized with a careful multiparametric evaluation, allowing classification of the MR into one of the two dichotomous categories.

The MitraClip System consists of a 24 Fr guide catheter and a clip delivery system, which includes one detachable clip [Figure 1]. The system is steerable using two knobs, which allow medial-lateral and anteriorposterior deflection; moreover, the clip delivery system includes a control mechanism by which the clip arms are opened and closed. The procedure is performed in the catheterization laboratory, under general anesthesia and with fluoroscopic and TEE guidance. A transseptal approach is used, and the puncture has to be performed in the posterosuperior part of the fossa ovalis, $4.5 \mathrm{~cm} \pm 0.5 \mathrm{~cm}$ from the MV plane, to guarantee optimal maneuverability of the clip delivery system in the left atrium. Therefore, the clip is aligned on the main regurgitation jet, perpendicularly to the MV line of coaptation. Subsequently, arms are opened with a $180^{\circ}$ angle, grippers are raised, the system is advanced into the LV and then retracted until reaching a position where firm grasping of both leaflets can be expected. Finally, the leaflets are grasped with grippers and clip arm closure and the presence of adequate "tissue-bridge" inside the device as well as the amount of residual MR and mitral gradient need to be evaluated. If the result is acceptable, the device is deployed by maneuvering the clip delivery system. If needed, particularly in complex anatomies (i.e., cleft, commissural flail, Barlow's disease, etc.), more than one clip may be positioned. In this case, residual MR and transvalvular gradients must be re-assessed for each additional clip. Main possible complications of the procedure include peripheral vascular injury, injury of surrounding cardiac structures during transseptal puncture, potentially causing cardiac tamponade requiring pericardiocentesis, clip detachment and embolization or clip entanglement in the chordae tendineae with possible damage ${ }^{[15]}$.

Compared to the first-generation device that was launched in 2008, the current generation includes two different versions: the MitraClip $\mathrm{NT}_{\mathrm{R}}$ and the MitraClip $\mathrm{XT}_{\mathrm{R}}$. The former is an evolution of the previous 

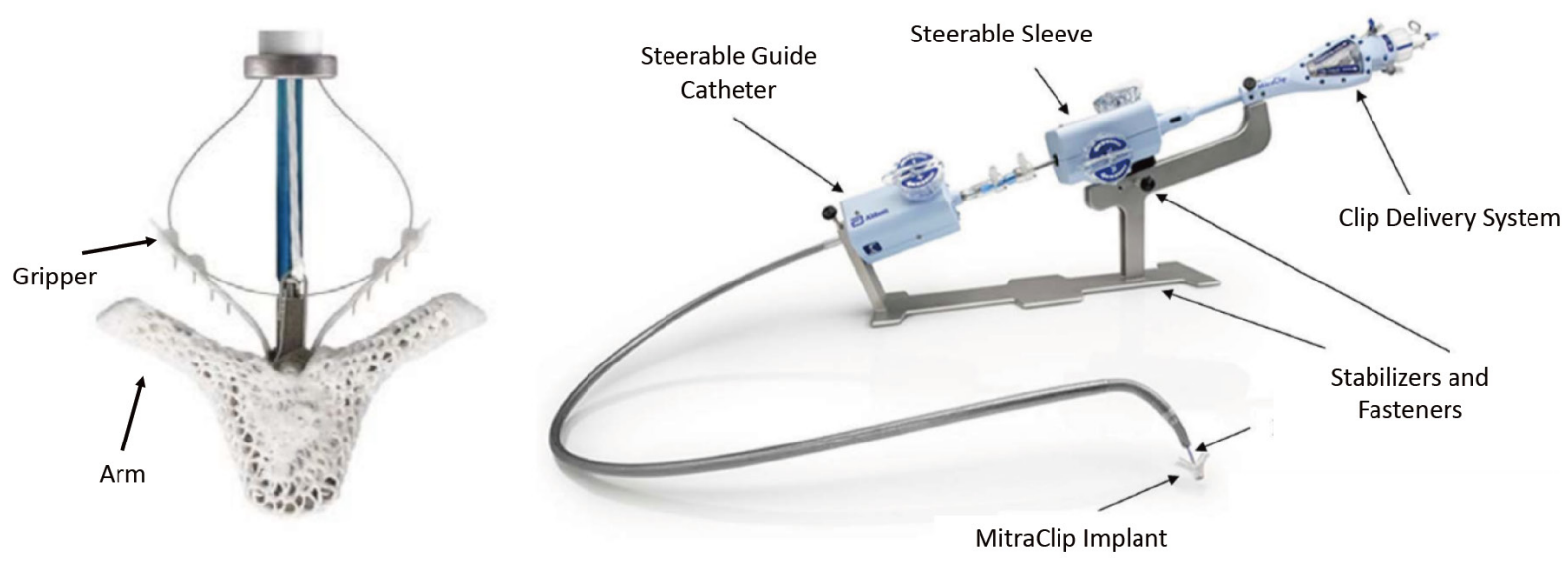

Figure 1. In the left panel, the MitraClip device is shown in its open configuration with grippers opened. Right panel shows the delivery system, consisting of a Steerable Guide Catheter and the Clip Delivery System (Steerable Sleeve, Delivery Catheter and Clip) which are steered and actuated using control knobs, levers and fasteners located on the handles

generation device (the MitraClip NT) with an enhanced delivery system, whereas the latter is a completely new version, with larger and longer arms and grippers that should allow a deeper and more stable grasping, particularly in case of large coaptation gaps or redundant MV tissue, frequently encountered in the degenerative settings.

The PASCAL Repair System consists of a 10-mm central spacer, intended to fill the regurgitation area, and two broad paddles intended to maximize leaflet coaptation and reduce stress on the grasping area (when closed, the paddles also dynamically flex on every heartbeat, as the valve opens and closes). The implant has clasps that allow for independent leaflet capture and offer the possibility to fine-tune leaflet positioning. The 22 Fr delivery system includes three catheters: a guide sheath, a steerable catheter, and an implant catheter used to deliver the implant. The three independent catheter movements in all planes allow access to different locations across the coaptation line and a very simple control of position and orientation of the device [Figure 2]. All these features were designed to overcome some of the technical limitations of the MitraClip system in complex anatomies, such as short posterior leaflet, large flail gaps, severe tethering, and severe annular dilatation ${ }^{[16]}$. Specifically, in a degenerative mitral regurgitation (DMR) setting: the independent catheters should simplify the navigation in the left atrium and the orientation of the device; the larger size of the implant should achieve effective MR reduction; and the wide paddles and optional independent leaflet grasping should ensure reaching a straight leaflet insertion in case of challenging anatomies, with no determinant impact on post-procedural MV gradient. However, further studies are needed to assess the safety and effectiveness of this novel device in this complex anatomical setting.

\section{EVIDENCE ON PERCUTANEOUS “EDGE-TO-EDGE” LEAFLET TREATMENT IN PRIMARY MR}

Current evidence about the efficacy and safety of the MitraClip in the setting of organic MR is mostly based on the initial EVEREST cohort, the EVEREST II randomized trial and single or multicenter worldwide registries [Table 2]. The EVEREST pilot study enrolled 107 patients, of which $79 \%$ presented with degenerative MR. Acute procedural success occurred in $74 \%$ of recruited patient and $9 \%$ experienced major adverse events (MAE) at 30-day follow-up. The primary efficacy endpoint, a composite of freedom from death, MV surgery and residual MR $>2+$, occurred in $66 \%$ of the population at 1 year and remained stable at 2 and 3 -year of follow up ${ }^{[13]}$, while $30 \%$ of patients had MV surgery up to 3 years after the clip procedure. In the randomized EVEREST II trial, the MitraClip system was compared to conventional MV surgery; 279 patients were enrolled and almost one-third of the population had complex degenerative MR with either Barlow's disease or anterior leaflet prolapse. The MitraClip procedure was associated with lower MAE incidence at 30 days follow-up $(48 \%$ vs. $15 \%, P<0.001)$. This primary safety endpoint was defined as the composite of death, myocardial infarction, reoperation for failed mitral valve surgery, nonelective 
Table 2. Real-world registries on safety and efficacy results of the MitraClip procedure

\begin{tabular}{|c|c|c|c|c|c|c|c|c|}
\hline Registry & $\begin{array}{c}\text { No. of } \\
\text { pts. }\end{array}$ & Age & $\begin{array}{c}\text { Primary } \\
\text { MR }\end{array}$ & $\begin{array}{c}\text { Procedural } \\
\text { success }\end{array}$ & $\begin{array}{c}\text { 30-day } \\
\text { mortality }\end{array}$ & $\begin{array}{c}\text { 1-year } \\
\text { mortality }\end{array}$ & $\begin{array}{c}\text { 1-year } \\
\text { MR grade } \leq \mathbf{2 +}\end{array}$ & $\begin{array}{c}\text { 1-year } \\
\text { NYHA class } \leq \text { II }\end{array}$ \\
\hline REALISM ${ }^{[26]}$ & 351 & $76 \pm 11$ & $30 \%$ & $86 \%$ & $5 \%$ & $23 \%$ & $83.6 \%$ & $82.9 \%$ \\
\hline ACCESS-EU ${ }^{[27]}$ & 567 & $74 \pm 10$ & $23 \%$ & $91 \%$ & $3 \%$ & $17 \%$ & $78.9 \%$ & $71.4 \%$ \\
\hline SENTINEL ${ }^{[28]}$ & 628 & $74 \pm 10$ & $23 \%$ & $95 \%$ & - & $15 \%$ & $94 \%$ & $74.2 \%$ \\
\hline TRAMI $^{[15,29]}$ & 828 & $76(71-81)$ & $29 \%$ & $97 \%$ & $5 \%$ & $20 \%$ & - & $63.3 \%$ \\
\hline GRASP-IT ${ }^{[30]}$ & 304 & $72 \pm 10$ & $21 \%$ & $92 \%$ & $3 \%$ & $13 \%$ & - & - \\
\hline STS/ACC TVT ${ }^{[31]}$ & 2952 & $82(74-86)$ & $86 \%$ & $92 \%$ & $5 \%$ & $26 \%$ & - & - \\
\hline MITRA-SWISS ${ }^{[32]}$ & 100 & $72 \pm 12$ & $38 \%$ & $85 \%$ & - & $15 \%$ & $78 \%$ & $80 \%$ \\
\hline
\end{tabular}

pts: patients; MR: mitral regurgitation; NYHA: New York Heart Association
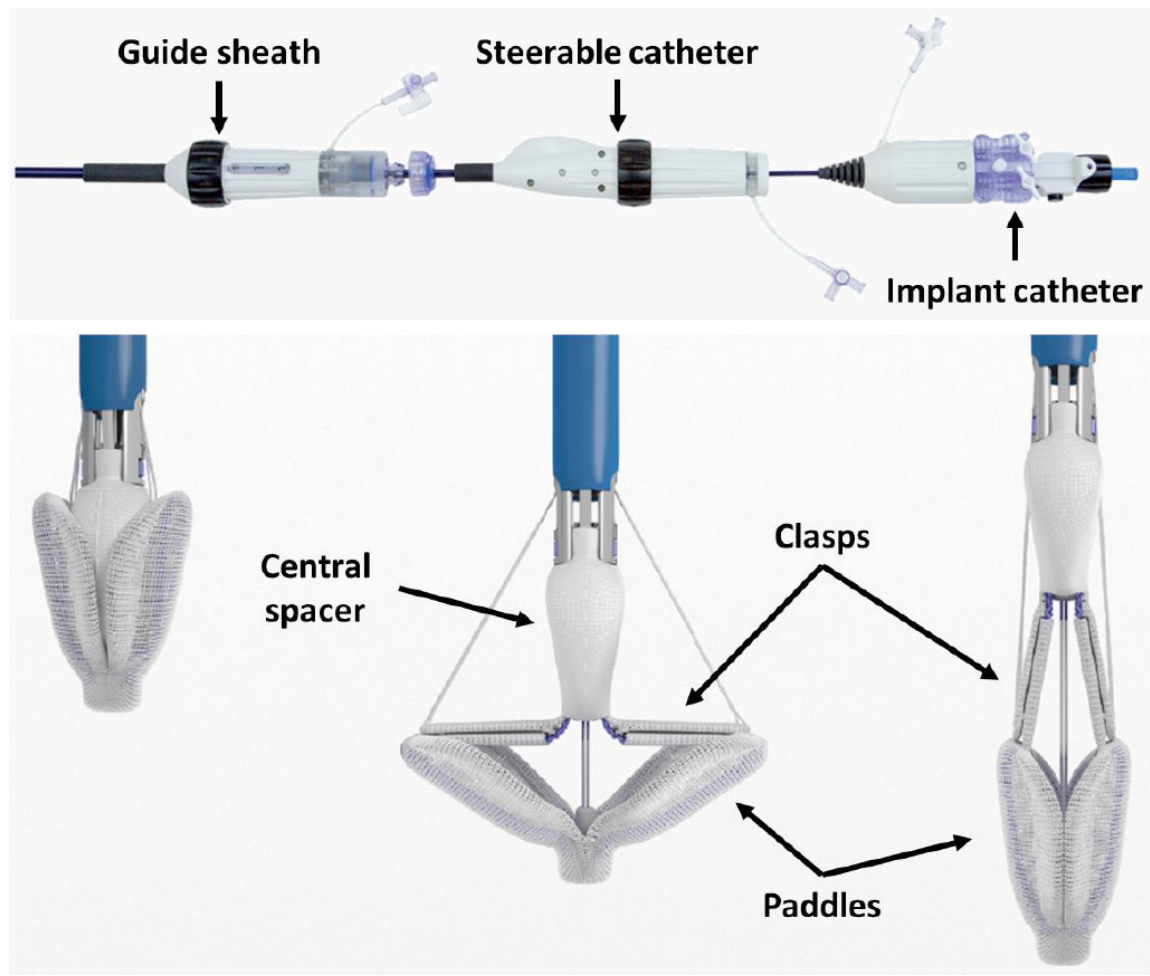

Figure 2. Upper panel shows the PASCAL Delivery System handle, comprising three different parts, one for each catheter. Independent movement of the three catheters is actuated by the use of control knobs. Lower panel shows the PASCAL implant in the closed, opened and elongated configurations (from left to right, respectively)

cardiovascular surgery for adverse events, stroke, renal failure, deep wound infection, mechanical ventilation for more than $48 \mathrm{~h}$, gastrointestinal complication requiring surgery, new-onset permanent atrial fibrillation, septicemia, and transfusion of 2 units or more of blood; to note, the former was the major driver of superiority for the MitraClip procedure. When considering any MAE excluding transfusion, no significant differences were observed between surgical and percutaneous treatment. At 12 months followup, the primary efficacy endpoint was greater in the surgical group compared to the percutaneous group (respectively $73 \%$ vs. 55\%, $P=0.007$ ) but with similar improvements in clinical outcomes such as LV size, New York Heart Association (NYHA) functional class and quality of life measures ${ }^{[17]}$. At a longer followup, patients requiring surgery for residual MR or MV dysfunction during the first year after treatment were more commonly those initially treated with percutaneous repair, but comparably low rates of surgery were observed in both groups between 1- and 5-year follow-up ${ }^{[18]}$. More recently, Buzzatti et al. ${ }^{[19]}$ showed lower acute postoperative complications and improved 1-year survival after MitraClip treatment compared to surgery in elderly patients (age $>75$ ) affected by primary MR and STS-PROM $<8 \%$. However, the percutaneous procedure was once again associated with greater MR recurrence and reduced survival 
beyond 1 year of follow-up. As a matter of fact, current clinical guidelines still recommend surgical valve repair as the gold standard for the treatment of primary MR, restricting the percutaneous "edge-to-edge" option to patients judged inoperable or at high surgical risk ${ }^{[2]}$. In this population, improvements in quality of life, NYHA functional class, LV reverse remodeling and reduction in heart failure hospitalizations are consistently observed after treatment with MitraClip ${ }^{[20]}$. Data on the new MitraClip $\mathrm{XT}_{\mathrm{R}}$ are still limited to initial experiences in selected patients with DMR and complex MV anatomies, such as Barlow's disease ${ }^{[21,22]}$. A large observational prospective study, the MitraClip EXPAND Study (NCT03502811) is designed to enroll up to 1000 patients to confirm the safety and performance of the $\mathrm{NT}_{\mathrm{R}}$ and $\mathrm{XT}_{\mathrm{R}}$ System, identifying trends in patient selection for MitraClip therapy in a real-world use.

Current data about the PASCAL Repair System are limited to the first-in-man study, which enrolled 23 patients ${ }^{[16]}$, and the CLASP study, a multicenter prospective single-arm study in 62 patients with primary and secondary moderate-to-severe or severe MR (36\% of degenerative etiology $)^{[23]}$. In the latter, successful implantation was achieved in $95 \%$ of patients. At 30 days, encouraging results were shown, with a MAE rate of $6.5 \%$, with an all-cause mortality rate of $1.6 \%$ and no occurrence of stroke; procedural residual MR grade $2+$ or less was achieved in $98 \%$ patients, and $85 \%$ were in NYHA functional class I or II. The mean 6 -min walk distance increased by $36 \mathrm{~m}$ from baseline and both the Kansas City Cardiomyopathy Questionnaire and EQ-5D Health Questionnaire scores improved significantly. Further results collecting 6-month and 1 -year follow-up have been recently presented showing sustained results compared to the previous one ${ }^{[24,25]}$. The forthcoming Edwards PASCAL CLASP IID/IIF Pivotal Clinical Trial (CLASP IID/IIF; NCT03706833) is the first randomized controlled trial that is going to specifically investigate the safety and effectiveness of the Pascal system compared to the MitraClip system in patients with degenerative MR at high or prohibitive risk for MV surgery by the Heart Team.

\section{CASE EXAMPLE: PRIMARY MR TREATED WITH THE MITRACLIP SYSTEM}

We report here the case of a 75-year-old man affected by symptomatic severe degenerative MR and a history of hypertension, paroxysmal atrial fibrillation and ischemic cardiopathy initially treated with triple coronary artery bypass graft and later with percutaneous coronary stenting on left main and circumflex artery because of venous graft occlusion. He also underwent mechanical aortic valve prothesis implantation because of severe aortic insufficiency and several comorbidities, including beta-thalassemia minor with moderate-to-severe anemia often requiring blood transfusions, chronic obstructive pulmonary disease, kyphoscoliosis, left kidney atrophy with chronic renal insufficiency and previous thoracic radiotherapy and splenectomy for the treatment of a Hodgkin's lymphoma. A 2D and 3D transthoracic echocardiogram showed a normal-sized left ventricle with preserved EF and unchanged regional wall motion abnormalities, a well-functioning mechanical aortic prothesis and a severe MR due to $\mathrm{P} 2$ leaflet prolapse extended to $\mathrm{P} 3$ and a $\mathrm{P} 1-\mathrm{P} 2$ cleft. Of note, calcification of the anterior leaflet was present outside the grasping area reducing mobility and producing a mean gradient of $3 \mathrm{mmHg}$. Left atrium was severely dilated, and a moderate tricuspid regurgitation was also detected, with a mean arterial pressure of $37 \mathrm{mmHg}$. These findings were confirmed with $2 \mathrm{D}$ and $3 \mathrm{D}$ TEE, which allowed us to positively assess anatomic suitability of MitraClip implant [Figure 3]. After multidisciplinary Heart Team clinical evaluation, the patient became a suitable candidate for percutaneous "edge-to-edge" repair, with an intended treatment strategy of implantation of two convergent clips. The procedure was carried out through a right femoral venous access and under fluoroscopic and both 2D and 3D TEE guidance. The transseptal puncture was done in a posterosuperior position of the fossa ovalis with a measured height of $4.3 \mathrm{~cm}$ over the atrioventricular plane. A guidewire was then positioned in the left superior pulmonary vein and the MitraClip delivery system was advanced into the left atrium [Figure 4]. Subsequently, the first clip was aligned on the main regurgitation jet in A2- $\mathrm{P} 2$ position with a slight counterclockwise orientation, arms were opened with a $180^{\circ}$ angle, grippers were raised, and the clip was advanced into the left ventricle. The system was then retracted to reach a stable grasping of both leaflets and clip arms were closed [Figure 5]. Therefore, after a careful TEE final assessment, the first clip was deployed. The same procedural steps were repeated for the placement of a 

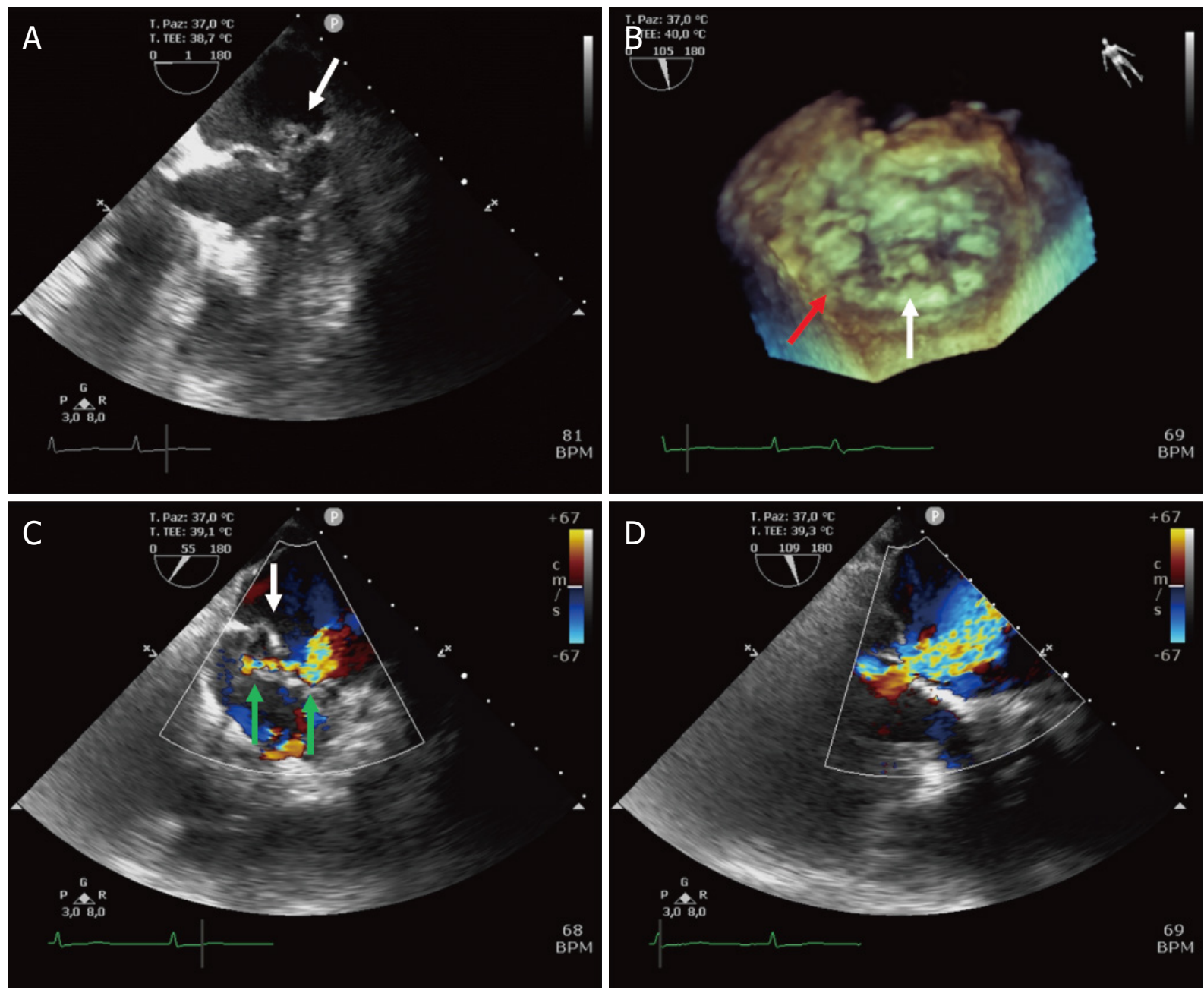

Figure 3. Preoperative evaluation with $2 D(A, C, D)$ and $3 D(B)$ TEE. White arrows indicate P2 prolapse; red arrow indicates P1-P2 cleft. Color TEE (C, D) shows 2 regurgitation jets (green arrows) with the main one localized at the level of P2 prolapse, producing severe mitral regurgitation
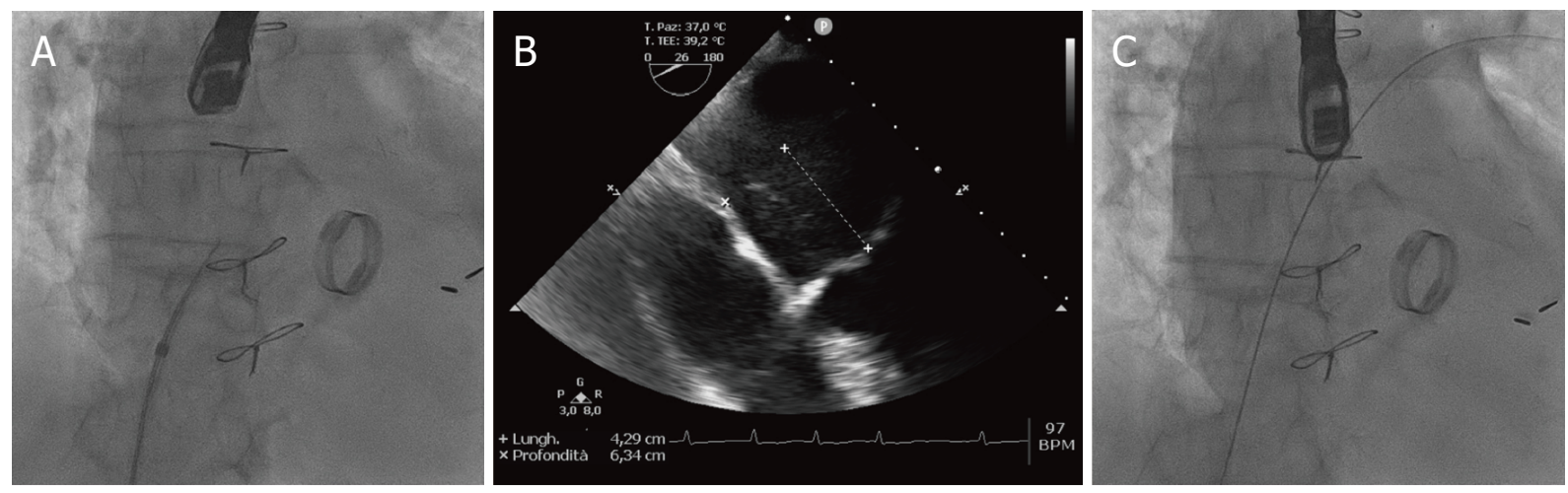

Figure 4. Transseptal puncture under fluoroscopic (A) and TEE (B) guidance. A puncture 4 to $4.5 \mathrm{~cm}$ above the MV plane in a posterosuperior position allows good maneuverability of the delivery system. After the transseptal puncture, a guidewire is introduced in the left atrium and then in the left superior pulmonary vein (C)

second clip lateral to the first one, with a slight clockwise orientation, in P1-A2 position [Figure 6]. At the end of the procedure, mild residual MR was detected with a mean gradient less than $5 \mathrm{mmHg}$ [Figure 7]. 

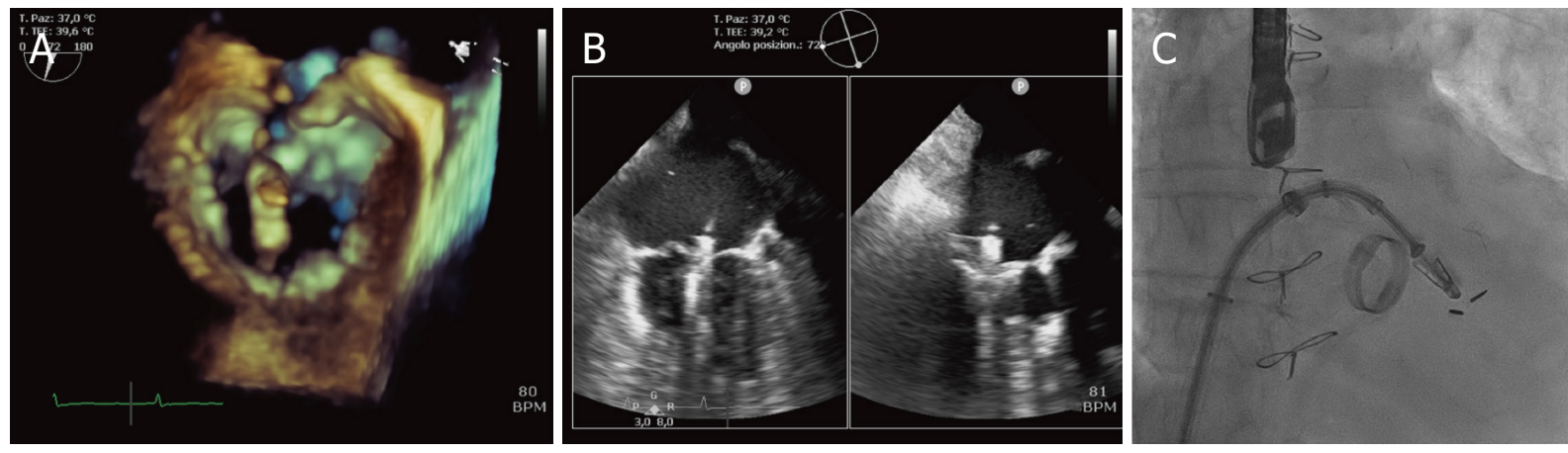

Figure 5. Implantation of a first MitraClip. The device is aligned with the main regurgitation jet at $\mathrm{P} 2$ prolapse, perpendicularly to the coaptation plane and slightly oriented counterclockwise (A); under TEE (B) and fluoroscopic (C) guidance, clip arms are opened, the device is advanced in the left ventricle and then retracted to grasp both leaflets
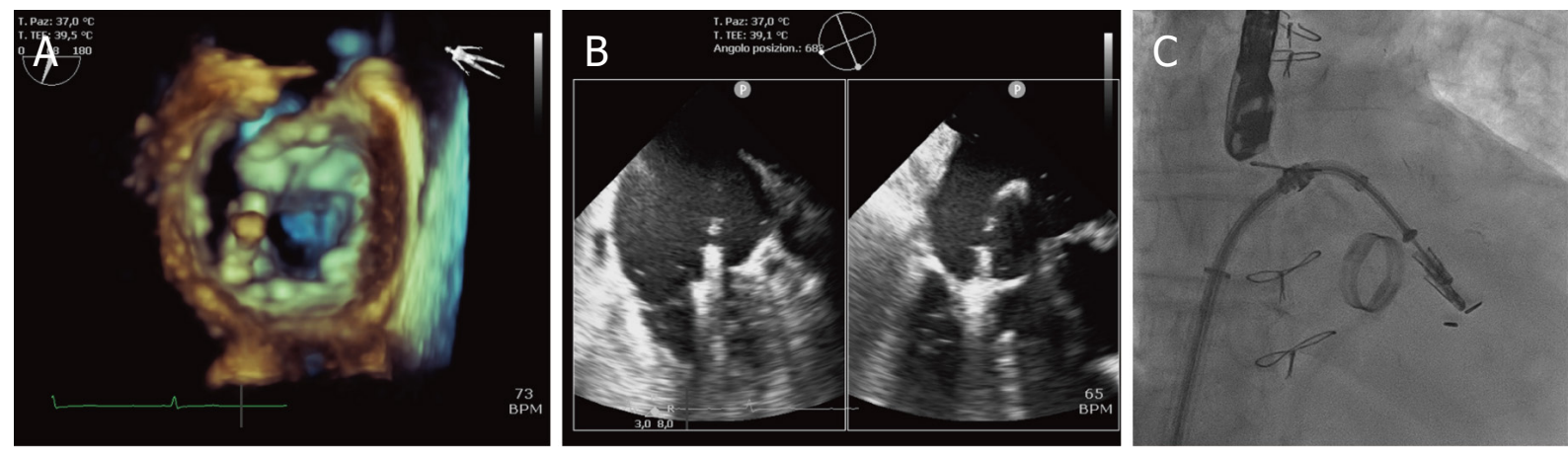

Figure 6. Implantation of a second MitraClip. The second device is placed in P1-A2 position with a slight clockwise orientation compared to the first Clip (convergent clip technique) under 3D TEE (A), X-plan view on TEE (B) and fluoroscopic (C) guidance
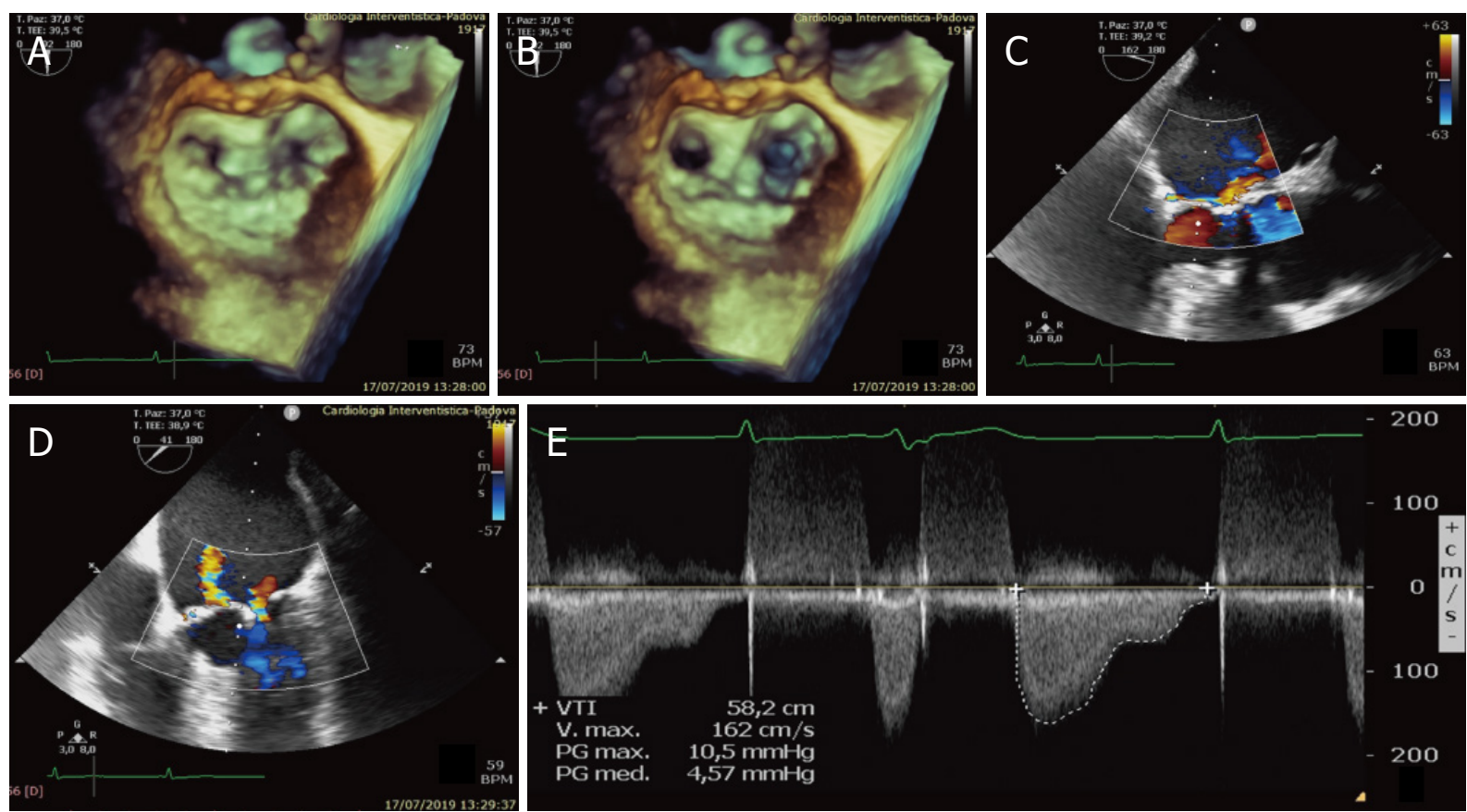

Figure 7. Final result. The 3D TEE shows the new "double orifice" mitral valve (A, B) with mild residual mitral regurgitation (C, D); continuous doppler (E) shows a final transvalvular gradient less than $5 \mathrm{mmHg}$ 
The patient was discharged after 3 days without peri-procedural complications. After 30 days, a followup transthoracic echocardiogram showed mild MR and stable transvalvular gradients. One year later the patient confirmed a clinical status improvement (NYHA functional class I-II) with no further hospital admissions for heart failure.

\section{DECLARATIONS}

\section{Authors' contributions}

Participated to the conception and the drafting of the manuscript, its critical revision for important intellectual content and the final approval of the submitted text; agreed for all aspects of the work ensuring that questions related to the accuracy or integrity of any part of the work are appropriately investigated and resolved: Rodinò G, Masiero G, Tarantini G

\section{Availability of data and materials}

Not applicable.

\section{Financial support and sponsorship}

None.

\section{Conflicts of interest}

Tarantini G reports honoraria for lectures from Abbott Vascular and Edwards Lifesciences; Rodinò G and Masiero $\mathrm{G}$ declared that there are no conflicts of interest.

\section{Ethical approval and consent to participate}

Not applicable.

\section{Consent for publication}

Not applicable.

\section{Copyright}

(c) The Author(s) 2020.

\section{REFERENCES}

1. Nkomo VT, Gardin JM, Skelton TN, Gottdiener JS, Scott CG, et al. Burden of valvular heart diseases: a population-based study. Lancet 2006;368:1005-11.

2. Baumgartner H, Falk V, Bax JJ, De Bonis M, Hamm C, et al; ESC Scientific Document Group. 2017 ESC/EACTS Guidelines for the management of valvular heart disease. Eur Heart J 2017;38:2739-91.

3. Iung B. A prospective survey of patients with valvular heart disease in Europe: The Euro Heart Survey on Valvular Heart Disease. Eur Heart J 2003;24:1231-43.

4. Antoine C, Mantovani F, Benfari G, Mankad SV, Maalouf JF, et al. Pathophysiology of degenerative mitral regurgitation: new 3-Dimensional imaging insights. Circ Cardiovasc Imaging 2018;11:e005971.

5. Adams DH, Rosenhek R, Falk V. Degenerative mitral valve regurgitation: best practice revolution. Eur Heart J 2010;31:1958-66.

6. Freed LA, Levy D, Levine RA, Larson MG, Evans JC, et al. Prevalence and clinical outcome of mitral-valve prolapse. N Engl J Med 1999;341:1-7.

7. Freed LA, Benjamin EJ, Levy D, Larson MG, Evans JC, et al. Mitral valve prolapse in the general population. J Am Coll Cardiol 2002;40:1298-304.

8. Kolibash AJ. Progression of mitral regurgitation in patients with mitral valve prolapse. Herz 1988;13:309-17.

9. Ma JI, Igata S, Strachan M, Nishimura M, Wong DJ, et al. Predictive factors for progression of mitral regurgitation in asymptomatic patients with mitral valve prolapse. Am J Cardiol 2019;123:1309-13.

10. Mirabel M, Iung B, Baron G, Messika-Zeitoun D, Détaint D, et al. What are the characteristics of patients with severe, symptomatic, mitral regurgitation who are denied surgery? Eur Heart J 2007;28:1358-65.

11. De Bonis M, Lapenna E, Alfieri O. Edge-to-edge Alfieri technique for mitral valve repair: which indications? Curr Opin Cardiol 2013;28:152-7. 
12. O'Gara P, Sugeng L, Lang R, Sarano M, Hung J, et al. The role of imaging in chronic degenerative mitral regurgitation. JACC Cardiovasc Imaging 2008;1:221-37.

13. Feldman T, Kar S, Rinaldi M, Fail P, Hermiller J, et al; EVEREST Investigators. Percutaneous mitral repair with the MitraClip system: safety and midterm durability in the initial EVEREST (Endovascular Valve Edge-to-Edge REpair Study) cohort. J Am Coll Cardiol 2009;54:686-94.

14. Li CH, Arzamendi D, Carreras F. Role of imaging techniques in percutaneous treatment of mitral regurgitation. Rev Esp Cardiol (Engl Ed) 2016;69:421-36.

15. Eggebrecht H, Schelle S, Puls M, Plicht B, von Bardeleben RS, et al. Risk and outcomes of complications during and after MitraClip implantation: Experience in 828 patients from the German TRAnscatheter mitral valve interventions (TRAMI) registry. Catheter Cardiovasc Interv 2015;86:728-35.

16. Praz F, Spargias K, Chrissoheris M, Büllesfeld L, Nickenig G, et al. Compassionate use of the PASCAL transcatheter mitral valve repair system for patients with severe mitral regurgitation: a multicentre, prospective, observational, first-in-man study. Lancet 2017;390:773-80.

17. Feldman T, Foster E, Glower DD, Kar S, Rinaldi MJ, et al; EVEREST II Investigators. Percutaneous repair or surgery for mitral regurgitation. N Engl J Med 2011;364:1395-406.

18. Feldman T, Kar S, Elmariah S, Smart SC, Trento A, et al; EVEREST II investigators. Randomized comparison of percutaneous repair and surgery for mitral regurgitation: 5-year results of EVEREST II. J Am Coll Cardiol 2015;66:2844-54.

19. Buzzatti N, Van Hemelrijck M, Denti P, Ruggeri S, Schiavi D, et al. Transcatheter or surgical repair for degenerative mitral regurgitation in elderly patients: a propensity-weighted analysis. J Thorac Cardiovasc Surg 2019;158:86-94.e1.

20. Lim DS, Reynolds MR, Feldman T, Kar S, Herrmann HC, et al. Improved functional status and quality of life in prohibitive surgical risk patients with degenerative mitral regurgitation after transcatheter mitral valve repair. J Am Coll Cardiol 2014;64:182-92.

21. Jorbenadze R, Schreieck J, Barthel C, Seizer P, Schlensak C, et al. Percutaneous edge-to-edge mitral valve repair using the new MitraClip XTR System. JACC Cardiovasc Interv 2018;11:e93-5.

22. Weinmann K, Markovic S, Rottbauer W, Keßler M. First experience with the MitraClip XTR device for extensive mitral valve prolapse (Barlow's disease). EuroIntervention 2018;14:e1276-7.

23. Lim DS, Kar S, Spargias K, Kipperman RM, O’Neill WW, et al. Transcatheter valve repair for patients with mitral regurgitation: 30-day results of the CLASP study. JACC Cardiovasc Interv 2019;12:1369-78.

24. Mazimba S, Lim SD, Kipperman R, Spargias K, Kar S, et al. Six-month outcomes from the multicenter, prospective study with the novel PASCAL transcatheter valve repair system for patients with mitral regurgitation in the CLASP study. J Card Fail 2019;25:S6.

25. Kar S, Ng M, Lim S, Walters D, Webb J, et al. TCT-91 1-year outcomes from the multicenter, prospective study with the novel PASCAL transcatheter valve repair system for patients with mitral regurgitation in the CLASP study. J Am Coll Cardiol 2019;74:B91.

26. Glower DD, Kar S, Trento A, Lim DS, Bajwa T, et al. Percutaneous mitral valve repair for mitral regurgitation in high-risk patients: results of the EVEREST II study. J Am Coll Cardiol 2014;64:172-81.

27. Maisano F, Franzen O, Baldus S, Schäfer U, Hausleiter J, et al. Percutaneous mitral valve interventions in the real world: early and 1-year results from the ACCESS-EU, a prospective, multicenter, nonrandomized post-approval study of the MitraClip therapy in Europe. J Am Coll Cardiol 2013;62:1052-61

28. Nickenig G, Estevez-Loureiro R, Franzen O, Tamburino C, Vanderheyden M, et al; Transcatheter Valve Treatment Sentinel Registry Investigators of the EURObservational Research Programme of the European Society of Cardiology. Percutaneous mitral valve edge-toedge repair: in-hospital results and 1-year follow-up of 628 patients of the 2011-2012 Pilot European Sentinel Registry. J Am Coll Cardiol 2014;64:875-84.

29. Puls M, Lubos E, Boekstegers P, von Bardeleben RS, Ouarrak T, et al. One-year outcomes and predictors of mortality after MitraClip therapy in contemporary clinical practice: results from the German transcatheter mitral valve interventions registry. Eur Heart J 2016;37:703-12.

30. Capodanno D, Adamo M, Barbanti M, Giannini C, Laudisa ML, et al; GRASP-IT Investigators. Predictors of clinical outcomes after edge-to-edge percutaneous mitral valve repair. Am Heart J 2015;170:187-95.

31. Sorajja P, Vemulapalli S, Feldman T, Mack M, Holmes DR Jr, et al. Outcomes with transcatheter mitral valve repair in the United States: an STS/ACC TVT registry report. J Am Coll Cardiol 2017;70:2315-27.

32. Sürder D, Pedrazzini G, Gaemperli O, Biaggi P, Felix C, et al. Predictors for efficacy of percutaneous mitral valve repair using the MitraClip system: the results of the MitraSwiss registry. Heart 2013;99:1034-40. 